\title{
Economic Perspective in the Production of Copper Nanowire using Amino Acids as Capping Agent
}

\author{
Puspa Sari Dewi, Asep Bayu Dani Nandiyanto* \\ Departemen Pendidikan Kimia, Fakultas Pendidikan Matematikadan Ilmu Pengetahuan Alam, \\ Universitas Pendidikan Indonesia, INDONESIA
}

Email*: nandiyanto@upi.edu

\begin{abstract}
The purpose of this study is to evaluate the economic feasibility of making copper nanowire using amino acids as a capping agent. The evaluation was conducted from two perspectives, namely engineering analysis and economic evaluation using parameters such as gross profit margin, payback period, breakeven points, and net present value. An economic evaluation was also carried out comparing the use of amino acids Glycine, Lysine, Proline, and Alanine to find out which amino acids were more profitable in the production of copper nanowire. Furthermore, the evaluation is done by estimating the ideal situation and several other state assumptions such as changes in raw material prices, labor costs, and also income tax. From the results of this study, Glycine is known as the most profitable amino acid to be used in this process. In addition, by using Glycine as an ideal condition, based on the results of the evaluation of all parameters, this project is classified as prospective to do. Although further studies must be carried out to develop this project, this study can be the basis for developing new methods of making copper nanowire on a large scale.
\end{abstract}

Keywords: Copper nanowire, economic evaluation, amino acid as capping agent

Received: 27/11/2019 - Accepted: 25/12/2019

\section{Introduction}

Copper nanomaterial is a material that is well known as a material that has many uses in various fields, including in the areas of catalysis [1], biomedicine [2], electronics, and sensors [3]. Copper nanowire is specifically used in electronics as a transparent conductor of the future replacing $\mathrm{Ag}$ nanowire [4]. Copper nanowire is a very promising substitute for $\mathrm{Ag}$ nanowire due to the difference in conductivity between copper and $\mathrm{Ag}$ which is the best conductivity material, only $6 \%$, with greater availability in nature[5]. Due to its diverse uses, a wide variety of $\mathrm{Cu}$ nanowire preparation techniques have been developed. The synthesis of $\mathrm{Cu}$ nanowire is usually based on the principle of reducing copper ions to copper with the help of surfactants or capping agents. Some $\mathrm{Cu}$ nanowire preparation methods that have been carried out are wet chemical reduction methods [6], chemical vapor deposition [7], template-assisted syntheses [8], and electronic deposition [9]. Surfactant or capping agent is an important aspect in the synthesis of nanomaterials to stabilize the $\mathrm{Cu}$ that is formed to form the desired nanomaterial with the appropriate dimensions. In general, there are two types of capping agents for the formation of
$\mathrm{Cu}$ nanowire, namely are from the group of amines and carboxylic acids. Agents with amine function include ethylenediamine, hexadeclyamine, and oleylamine. While agents with carboxylic acid groups are oleic acid, lactic acid, and glycolic acid [5]. In the literature [5], a new $\mathrm{Cu}$ nanomaterial preparation method is developed using amino acids as a capping agent because it has an amine group and a carboxylic acid group. The results of the literature state that the use of amino acids Glycine, Alanine, Lysine, and Proline can produce $\mathrm{Cu}$ nanowire that is good and homogeneous. The use of amino acids as a capping agent is interesting because it uses materials that are environmentally friendly, versatile, and low cost. But until now, there has been no literature that does economic valuation of the method to see its potential to be carried out on an industrial scale.

Therefore, this study was conducted to analyze the method in the literature [5] and evaluate the economy from an economic perspective in the production of copper nanowire using amino acids as capping agents to see its feasibility if scaled-up to the method. 
Evaluation is carried out by looking at the project from an engineering and economic perspective. In this study also carried out a comparison of economic evaluations of the use of Glycine, Lysine, Alanine, and Proline to determine the amino acids that are most suitable for use on an industrial scale, which are then used as ideal conditions. Several other evaluations were conducted, namely economic evaluation in ideal conditions, evaluation with variations in raw material prices, variations in labor costs, and variations in income tax to see the effect of various aspects of the project's cumulative net present value.

\section{Method}

\section{II.1. Theoretical Synthesis of Cu Nanowires}

Copper nanowire can be synthesized by reducing copper ions in an alkaline solution, with the help of amino acids as capping agent. Copper nanowire synthesis in this paper was adopted from the paper [5]. Synthesis begins by adding $15 \mathrm{M} \mathrm{NaOH}$ solution to the copper nitrate solution in water, then adding the selected amino acid as a capping agent, and $35 \%$ hydrazine. The mixture is then stirred slowly at a heating temperature of $80^{\circ} \mathrm{C}$. This process will produce a color change from blue to white then to brick red. $\mathrm{Cu}$ nanowire will begin to appear and float to the top layer of solution. After that, the suspension is filtered and the filtrate is washed with water, and then dried with a vacuum dryer. The reaction is carried out following the scheme in Figure 1 below. Chemical reactions that occur in the process of $\mathrm{Cu}$ nanowire synthesis are as follows:

$$
2 \mathrm{Cu}\left(\mathrm{NO}_{3}\right)_{2}+4 \mathrm{NaOH}+\mathrm{N}_{2} \mathrm{H}_{4} \rightarrow 2 \mathrm{Cu}+\mathrm{N}_{2}+4 \mathrm{NaNO}_{3}+4 \mathrm{H}_{2} \mathrm{O}
$$

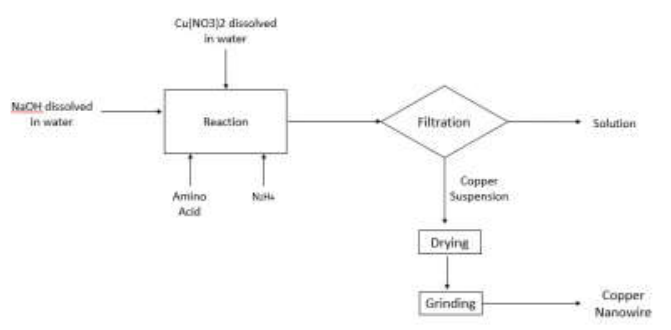

Figure 1. Reaction Flow Chart

\section{II.2. Engineering Perspective Evaluation}

An evaluation from an engineering perspective was conducted to examine the feasibility of $\mathrm{Cu}$ nanowire production with this method in terms of engineering. This evaluation is carried out based on the process flow diagram scheme in Figure 2. The first process is carried out by dissolving sodium hydroxide and copper nitrate in water in different mixers. The water used is river water that has been treated so that it becomes distilled water. Then by using a pump, the two solutions then entered into the reactor with a heater, then also added the selected amino acid and hydrazine. Heating the reactor for this reaction is done by the heat exchanger method. After being reacted, the mixture is then filtered to separate the suspension and the solution. The suspension is then dried, ground, separated, and then copper nanowire is obtained. Evaluation from the engineering side is based on paper [5] with the following assumptions, including all chemical compounds used in the production of $\mathrm{Cu}$ Nanowire are scaled up to 150,000 times the amount stated in the literature [5]. Detailed are:

- The reaction conversion rate is assumed to be $100 \%$

- There was a mass loss of the chemical compound transferred by $5 \%$ of the initial mass in each transfer process

- $\mathrm{Cu}$ nanowire obtained is as much as $80 \%$ of the stoichiometric calculation because it is assumed that loss occurs in each process of removal of nanowire $\mathrm{Cu}$ after synthesis

- The water used in the production process is purified, deionized water obtained from the water treatment plant provided at the plant

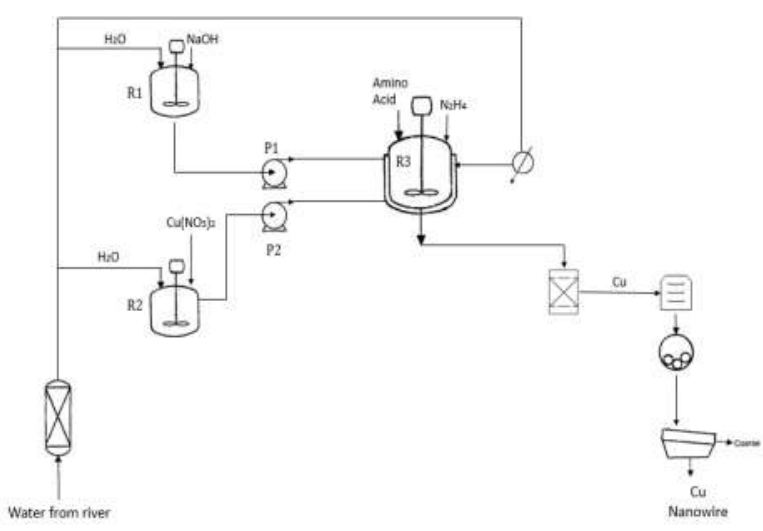

Figure 2. Process Flow Diagram of Copper Nanowire Production

\section{II.3. Economic Evaluation}

The economic feasibility study conducted is to examine the feasibility of $\mathrm{Cu}$ nanowire production by analyzing the prices of production components such as raw materials, equipment, utilities, and labor and its relation to the feasibility of large-scale production. The prices analyzed were obtained from various online shopping sites such as alibaba and tokopedia. The data was then calculated mathematically to produce a variety of economic evaluation parameters as follows:

1) GPM (gross profit margin) to predict economic evaluation roughly,

2) PBP (payback period) to estimate the time needed until profits are obtained,

3) BEP (break-even point) to get the minimum production capacity 
4) CNPV (cumulative net present value) to predict and evaluate project conditions as a function of time (in years).

The evaluation from the economic side is carried out with the assumptions below:

- The price of all equipment is adopted from several online buying and selling sites such as Alibaba, Tokedia, and Bukalapak

- Raw material prices have been adopted from several online selling sites on alibaba from Xi'an manufacturer Huilin Bio-Tech. The price of each chemical compound used in this evaluation is as follows: $\mathrm{Cu}\left(\mathrm{NO}_{3}\right)_{2} \mathrm{Rp} 61,110$ per $\mathrm{kg}, \mathrm{NaOH} \mathrm{Rp} 7,070$ per $\mathrm{kg}$, hydrazine $35 \% \mathrm{Rp} 42,635$ per $\mathrm{kg}$, Glycine Rp71,058 per kg, Alanine Rp141,432 per kg, lysine Rp183,861 per kg, Proline Rp141,432 per kg.

- The period of production evaluated is 10 years

- In one day of production, $\mathrm{Cu}$ Nanowire produced $1.72 \mathrm{~kg}$

- Utility cost is Rp. 1,467/ kWh. The amount paid in a year is Rp. 49,291,200

- Labor wages in ideal conditions for 10 people are $\mathrm{Rp}$. 720,000,000 per year

- All prices obtained in USD are converted to IDR with a conversion value of 1 USD $=$ IDR 14,150

- Income tax under ideal conditions is $10 \%$

- Discount rate is assumed to be $15 \%$

\section{Result and discussion}

\section{III.1. Engineering Perspective}

This synthesis is carried out with the principle of reducing $\mathrm{Cu} \quad\left(\mathrm{NO}_{3}\right)_{2}$ in basic conditions to $\mathrm{Cu}$. The formation of nanowire is carried out with amino acids that function as capping agents. In this paper, we evaluate the use of four different amino acids that can form $\mathrm{Cu}$ nanowire, namely glycine, lysine, alanine, and proline. The reducing agent in this reaction is hydrazine $35 \%$ with $15 \mathrm{M} \mathrm{NaOH}$ to make alkaline condition. All of the reducers are reacted in a reactor with a heater to form a brick red solution with a copper suspension. The suspension is then filtered using a vacuum filter and then dried using an oven dryer. The dried copper is then through a grinding process to form the final product, copper nanowire.

\section{III.2. Economic Evaluation of Feasibility Use of Various Amino Acids as Capping Agent in Preparation of Cu Nanowire}

The graph in Figure 3 shows the CNPV / TIC of lifetime with four different kinds of amino acids as capping agents, namely Glycine, Alanine, Lysine, and Proline. This variation is done with the assumption that the production capacity of each variation is the same, but with different raw material prices according to the price of each amino acid, so it can be seen that the most profitable amino acids to be used as a capping agent in $\mathrm{Cu}$ nanowire production .

On all four curves, there is a decrease in profits from 0 to about 2 years. This decrease occurred at an early stage of production due to initial costs such as costs for equipment, construction costs, and starting-up fees. In all circumstances, an increase in profit begins in the second year as the production process begins. After 2.5 years, there was a return on investment cost or a payback period. By comparing the four curves that represent economic evaluations of the use of four different amino acids, it can be seen that the use of a Glycine capping agent is more beneficial than other amino acids. Meanwhile, the profitability of using Alanine and proline did not differ significantly, and the use of lysine was less beneficial than the other three amino acids. The use of different amino acids will cause changes in variable costs due to differences in the price of raw materials used and differences in the amount. Raw material prices greatly affect the variable costs that will affect the profitability of this project [10]. The difference in quantity of amino acids due to the amount used is in the same number of moles, but due to different molecular masses, the quantity of amino acids in kilograms is also different. In molecular mass, Glycine is the lightest amino acid compared to the other three amino acids, so the price of raw material using Glycine is relatively lower than other amino acids.

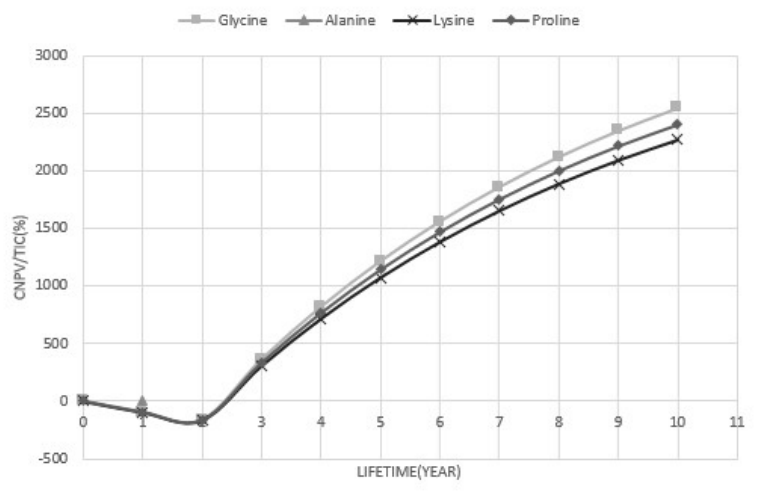

Figure 3. CNPV / TIC graph for Lifetime with Various Amino Acids as a Capping Agent for Making $\mathrm{Cu}$ Nanowire

\section{III.3. Evaluation of Ideal Conditions}

The graph in Figure 4 shows the curve of the NPV / TIC C relationship to lifetime under ideal conditions using Glycine as a capping agent. From the picture CNPV / TIC changes from year to year for ten years of production. Decrease in profits occurred from 0 to about 2 years. This decrease occurred in the early stages of production because of the initial cost of the project. Increased profits began do occur in the second year as the production process began. After 2.5 years, there was a return on investment cost or a payback period. The analysis was also carried out by calculating several economic evaluation parameters contained in 
Table 1. All economic evaluation parameters showed positive and promising results. GPM, BEP, and CNPV final year show that this project is very promising in terms of revenue. PBP for the capital market standard of USD 250,000 in Indonesia usually takes 1-2 years so, with this project investment of 300,000 USD, this project is still considered competitive. IRR for a 10 -year project period is $191 \%$, so that the annual IRR is estimated to reach $19.1 \%$. This IRR value is classified as high and also will not create conflict with Bank Indonesia interest which reaches $5-6 \%[11]$. Based on this analysis, the $\mathrm{Cu}$ nanowire synthesis project with Glycine as a capping agent was declared profitable to be carried out on an industrial scale.

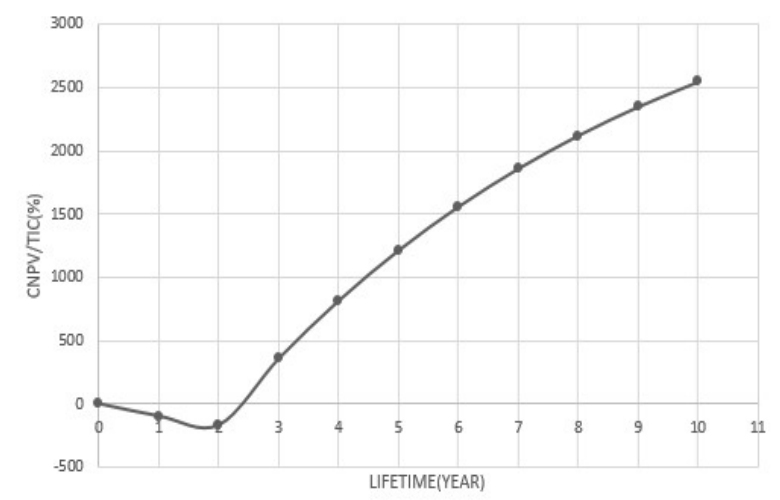

Figure 4. CNPV/TIC Graph to Lifetime for Ideal Condition

Table 1. Economic Evaluation Parameters in Ideal Conditions

\begin{tabular}{|c|c|}
\hline Economic Evaluation Parameter & Value \\
\hline GPM/year & Rp40,662,601,314 \\
\hline PBP & 2.5 year \\
\hline BEP & 10429.31 units \\
\hline Final Year CNPV & Rp101,295,984,748 \\
\hline IRR & $191 \%$ \\
\hline
\end{tabular}

\section{III.4. Economic Evaluation with Variations in Raw Material Prices}

The graph in Figure 5 shows the CNPV / TIC relationship curve to lifetime with a comparison of several different raw material values. Five variations in the value of raw material were carried out, namely curves under ideal conditions, raw material values varied by $-100 \%,-50 \%,+50 \%,+100 \%$ of the value of raw material in ideal conditions. This variation is done with the assumption that the production capacity in each variation is the same as the production capacity under ideal conditions, but with different raw material prices. This evaluation was conducted to analyze the effect of changes in raw material prices on the profits of $\mathrm{Cu}$ Nanowire production. CNPV / TIC value changes from year to year. There was a decrease from $0-2$ in all variations, according to the curves under ideal conditions. This decrease occurred because of the initial capital condition carried out before the production process began. In all variations, the profile began to be generated in the second year.

By comparing the five different raw material price conditions in figure 5 , it can be realized that this project is still profitable to do if the production is carried out with raw material prices of $-100 \%,-50 \%,+50 \%,+$ $100 \%$ of the value of raw material in ideal conditions. However, the difference is seen in the rate of increase in CNPV / TIC annually. From the graph, it can be concluded that the greater the price of raw material used, the rate of increase of CNPV / TIC is slower. This means that with the price of raw materials increasing, the rate of profit income decreases. This happens because raw material is closely related to overall production costs. With the same number of sales, an increase in production costs will reduce profits. With the production capacity and sales that remain, an increase in production costs will reduce profits. The increase in raw material prices has a negative impact on this project [12]. However, this evaluation is also known that the project is still profitable to do even if the price of raw materials is greater $100 \%$ of the price of raw material on condition the ideal.

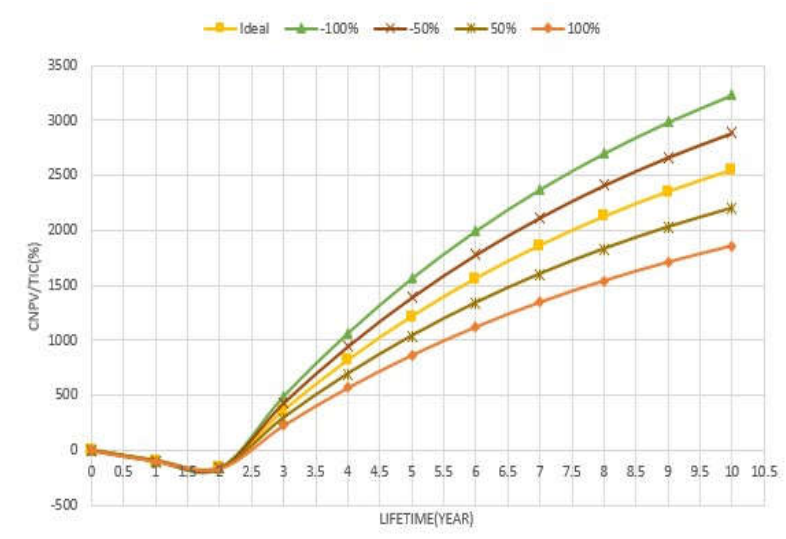

Figure 5. CNPV/TIC graph with Variations in Raw Materials

\section{III.5. Economic Evaluation with Labor Cost Variations}

The graph in Figure 6 shows the CNPV / TIC relationship curve to lifetime with a comparison of several different labor cost values. Five variations in the value of labor cost were carried out, namely the curve under ideal conditions, the value of raw material varied by $+50 \%,+100 \%,+150 \%,+200 \%$ of the value of labor cost under ideal conditions. This variation is done with the assumption that the number of workers in each variation is equal to the number of workers in ideal conditions, namely 10 people, but with different salary prices, so that it can be seen the effect of changes in labor cost prices on $\mathrm{Cu}$ Nanowire production profits. CNPV / TIC value changes from year to year. There was a decrease from $0-2$ in all variations, according to the curves under ideal conditions. This 
decrease occurred because the initial cost of setting up the project carried out before the production process begins. In all variations, ranging generated profit in the year to 2 .

From the chart on figure 6 , it is known that the rate of increase of CNPV / TIC will decrease along with the increase in labor costs incurred. This happens because labor cost is one aspect of production costs related to profits derived from the project. However, despite the decline in the rate, it can be concluded that the change in the price of labor cost does not have a significant effect on the rate of increase CNPV / TIC.

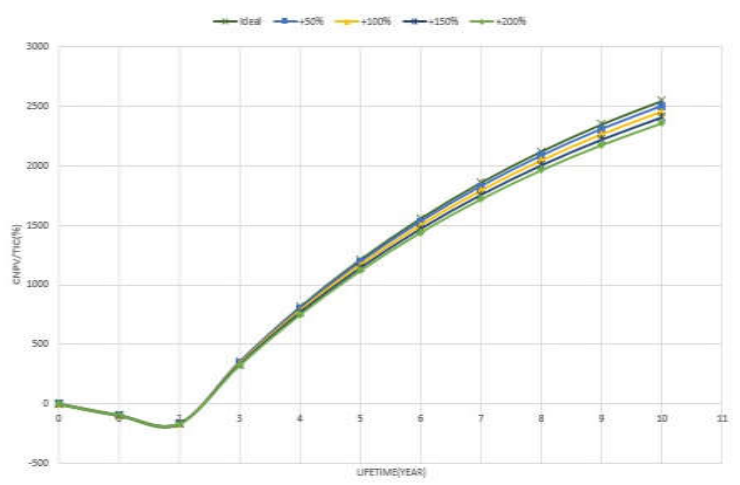

Figure 6. CNPV/TIC graph with Variations in Labor Cost

\section{III.6. Economic Evaluation with Variations in Income Tax}

The graph in Figure 7 shows the CNPV / TIC relationship curve to lifetime with a comparison of several different income tax values. This variation is done to see the impact of external conditions, namely taxes, which can affect this project. Five variations in the value of income tax were made, namely $25 \%, 50 \%$, and $75 \%$ with income tax under ideal conditions of $10 \%$. This variation is done with the assumption that the production capacity is the same, but with a different amount of income tax. CNPV / TIC value changes from year to year. There was a decrease from $0-2$ in all variations, according to the curves under ideal conditions. This decrease occurred because the initial cost of setting up the project carried out before the production process begins. In all variations, profits start to be generated in the second year.

From The chart in figure 7 , it is known that the rate of increase of CNPV / TIC will decrease along with the increase in income tax. Income tax has a significant effect on the CNPV / TIC rate so that there is a difference in payback period that is different in each scenario. In ideal conditions and $25 \%$ income tax conditions, the payback period occurs before the 2.5 th year. In the $50 \%$ income tax condition, the payback period occurs after the 2.5 year and in the $75 \%$ income tax condition, the payback period occurs in the 3rd year.

From the graph it is known that ideal conditions are the most profitable conditions. It also appears that the increase in tax will reduce revenue and also have an impact on PBP which is getting longer to be achieved. This occurs because the incoming cash flow will be reduced due to truncated by the income tax incurred thereby reducing incoming profit [11].

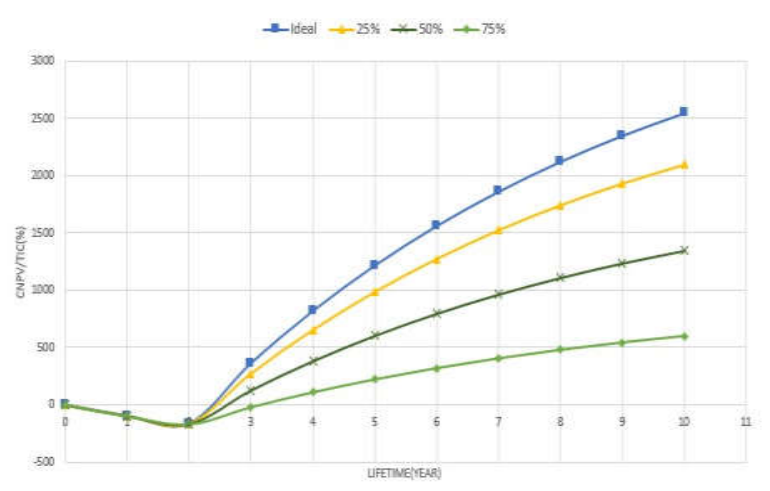

Figure 7. CNPV/TIC graph with Variations in Income Tax

\section{Conclusion}

Based on the analysis that has been done, the copper nanowire production project using amino acids as a capping agent, in terms of engineering and economics, is a prospective project. The results of comparative analyzes with various amino acids show that the use of Glycine is more profitable compared to the use of Alanine, Proline, and lysine. By using Glycine as a capping agent in economic analysis under ideal conditions, analysis of some economic parameter values shows a positive value. So this project can be said to be prospective and very profitable.

\section{References}

[1] Y. Liao, G. Yu, Y. Zhang, T. Guo, F. Chang, and C. J. Zhong, "Composition-tunable $\mathrm{PtCu}$ alloy nanowires and electrocatalytic synergy for methanol oxidation reaction", ournal of Physical Chemistry C, Vol. 120, No. 19. 2016.

[2] B. Maria, "Single-Crystalline Copper Nanowires Produced Track Membranes", Advanced Materials No. 1, pp. 1999-2002, 2001.

[3] H. Xiang, T. Guo, M. Xu, H. Lu, S. Liu, and G. $\mathrm{Yu}$, "Ultrathin Copper Nanowire Synthesis with Tunable Morphology Using Organic Amines for Transparent Conductors", ACS Appl. Nano Mater., Vol. 1, No. 8, pp. 3754-3759, 2018.

[4] V. B. Nam and D. Lee, "Copper nanowires and their applications for flexible, transparent conducting films: A review", Nanomaterials, Vol. 6, No. 3, 2016.

[5] J. C. Yu, F. G. Zhao, W. Shao, C. W. Ge, and W. S. Li, "Shape-controllable and versatile synthesis of copper nanocrystals with amino acids as capping agents", Nanoscale, Vol. 7, No. 19, pp. 8811-8818, 2015.

[6] J. Tanori and M. P. Pileni, "Control of the shape 
of copper metallic particles by using a colloidal system as template", Langmuir, Vol. 13, No. 4, pp. 639-645, 1997.

[7] Y. Zhao, Z. Zhang, Y. Zhang, Y. Li, Z. He, and $\mathrm{Z}$. Yan, "Large-scale synthesis of $\mathrm{Cu}$ nanowires with gradient scales by using 'hard' strategies and size effects on electrical properties", Cryst Eng Comm, Vol. 15, No. 2, pp. 332-342, 2013.

[8] C. F. Monson, A. T. Woolley, "DNA-templated construction of copper nanowires," Nano Lett., Vol 1. 3, No 3, pp. 359-363, 2003.

[9] $\mathrm{H} . \mathrm{Wu}$, "Electrospun metal nanofiber webs as high-performance transparent electrode", Nano Lett, Vol. 10, No. 10, pp. 4242-4248, 2010.

[10] B. Prabowo, T. Khairunnisa, A.B.D. Nandiyanto, "Economic Perspective in the Production of Magnetite $\left(\mathrm{Fe}_{3} \mathrm{O}_{4}\right)$ Nanoparticles by Coprecipitation Method ", World Chemical Engineering Journal, Vol. 2, No. 2, pp. 1-4, 2018.

[11] A. B. D. Nandiyanto, "Cost Analysis and Economic Evaluation for The Fabrication of Activated Carbon and Silica Particles from Rice Straw Waste", Journal of Engineering Science and Technology, Vol. 13, No. 6, pp. 1523-1539, 2018.

[12] F. Nandatamadini, S. Karina, A.B.D. Nandiyanto, Nandiyanto, "Feasibility Study Based on Economic Perspective of Cobalt Nanoparticle Synthesis with Chemical Reduction Method", Cakra Kimia Vol. 7, pp. 62-68, 2019. 